\title{
Mesoporous poly(vinylidene fluoride-co-trifluoroethylene) membranes for lithium-ion battery separators
}

\author{
C. M. Costa ${ }^{1,2, \#, *}$, M. Kundu ${ }^{3,4, \#, ~ J . ~ C . ~ D i a s ~}{ }^{1,2}$, J. Nunes-Pereira ${ }^{1,5}$, G. Botelho ${ }^{2}$, \\ M. M. Silva ${ }^{2}$, S. Lanceros-Méndez, ${ }^{6,7 *}$
}

\#equal contribution

${ }^{1}$ Centro de Física, Universidade do Minho, Campus de Gualtar, 4710-057 Braga, Portugal

${ }^{2}$ Centro de Química, Universidade do Minho, Campus de Gualtar, 4710-057 Braga, Portugal

${ }^{3}$ Department of Chemistry, SRM University, Kattankulathur, 603203 Tamil Nadu, India ${ }^{4}$ Department of Material Science and Engineering, Norwegian University of Science and Technology (NTNU), NO-7491 Trondheim, Norway

${ }^{5}$ C-MAST - Centre for Mechanical and Aerospace Science and Technologies, Universidade da Beira Interior, Rua Marquês d'Ávila e Bolama 6200-001 Covilhã, Portugal

${ }^{6} \mathrm{BCMaterials,} \mathrm{Basque} \mathrm{Center} \mathrm{for} \mathrm{Materials,} \mathrm{Applications} \mathrm{and} \mathrm{Nanostructures,} \mathrm{UPV/EHU}$ Science Park, 48940 Leioa, Spain

${ }^{7}$ IKERBASQUE, Basque Foundation for Science, 48013 Bilbao, Spain

*Corresponding Authors Email: C. M. Costa (cmscosta@fisica.uminho.pt); S. Lanceros-Méndez (senentxu.lanceros@bcmaterials.net) 


\begin{abstract}
Mesoporous separator membranes based on poly(vinylidene fluoride-cotrifluoroethylene), PVDF-TrFE, were prepared through the removal of $\mathrm{ZnO}$ nanoparticles from the polymer matrix composite. Different filler concentrations were used, and the evaluation of the morphology, mechanical properties, uptake and ionic conductivity of the membranes were demonstrated that they depend on initial $\mathrm{ZnO}$ content in the composite. On the other hand, the vibration peaks characteristics of PVDF-TrFE and the thermal properties are independent on initial filler content. The membrane with the best ionic conductivity, $1.6 \mathrm{mS} / \mathrm{cm}$, is the one prepared after $70 \mathrm{wt} . \% \mathrm{ZnO}$ removal. The separator membranes were assembled in $\mathrm{Li} / \mathrm{C}-\mathrm{LiFePO}_{4}$ half-cells exhibiting good rate capability and cycling performance, the best battery performance being obtained for the PVDF-TrFE after 70wt.\% $\mathrm{ZnO}$ removal. The good performance of the developed separators was also demonstrated in full battery cells. Thus, a way to tailor membrane mesoporosity is presented and it is shown that the obtained membranes represent suitable separators for lithium-ion battery applications.
\end{abstract}

\title{
Graphical abstract
}

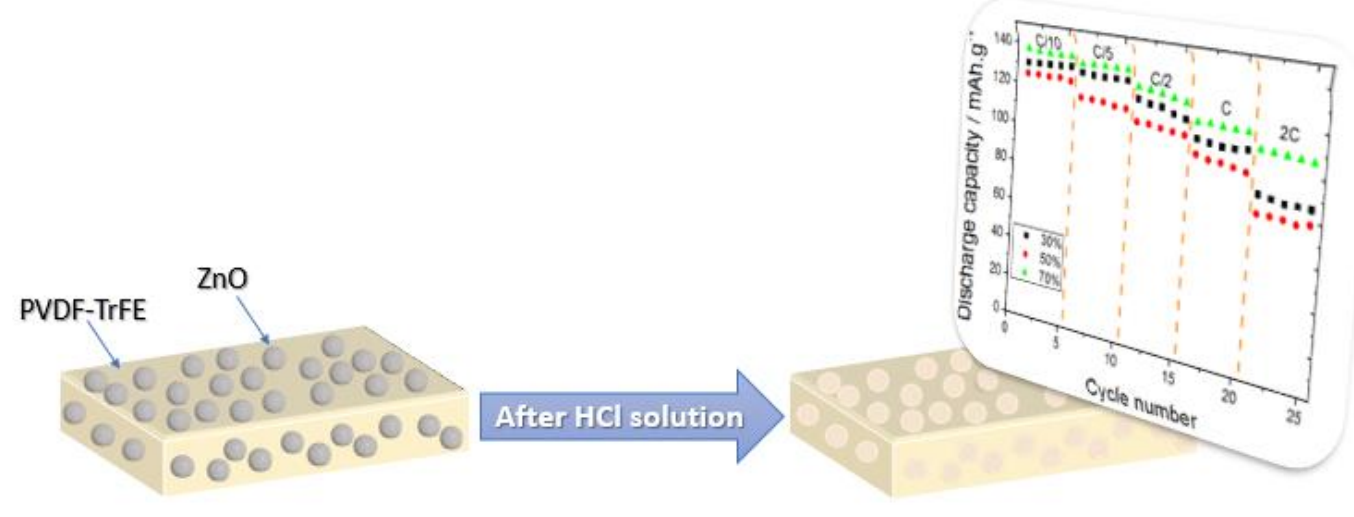

Keywords: Porosity; membranes; PVDF-TrFE; ZnO; battery separator 


\section{Introduction}

An increasingly technological society resulting from the growth of electronic miniaturization and the appearance of new gadgets has led to a growing demand for smaller and lighter energy storage systems with improved safety, energy and power characteristics $[1,2]$. These energy storage systems are not just used for portable consumer devices but are becoming relevant in transportation, such as electric vehicles (EVs), leading to a society highly dependent on energy storage systems [3, 4].

One of the most efficient technologies for energy storage are lithium-ion batteries, which are expected to become increasingly relevant for the next-generation rechargeable batteries [5-7].

Lithium-ion batteries present some advantages as power sources, as they are lighter, cheaper, show higher energy density $\left(290 \mathrm{Wh} \mathrm{kg}^{-1}\right)$, less charge loss, no memory effect, prolonged service-life, and higher number of charge/discharge cycles, when compared to other battery technologies $[8,9]$.

Lithium-ion batteries are fabricated from three key components: anode, cathode and a separator membrane, which is typically soaked by a electrolyte solution (liquid electrolyte where salts are dissolved in aqueous or organic solvents) [10]. The main functions of the separator membrane is to become the medium for ions transfer between the electrodes, prevent contact between the anode and the cathode, regulate cell kinetics and promote safety in the charge and discharge mechanisms [11]. The incorporation of the lithium solution into the separator membrane is usually achieved by uptake, i.e. the immersion of the polymer membrane directly into the lithium solution until the weight remains unchanged [12]. The properties of the separator membrane are dependent on the polymer membrane characteristics, including thickness, permeability, overall porosity, pore size and interconnectivity, wettability, electrolyte absorption and retention, chemical, thermal and mechanical stability [13].

Different processing techniques have been used to obtain porous membranes for battery applications, including template synthesis [14], dry and wet processes [15, 16], electrospinning [17], preirradiation grafting [18] and solvent casting techniques with thermally induced phase separation (TIPS) $[19,20]$ or non-solvent induced phase separation [21], among others. The most used host polymer types are poly(ethylene) (PE) [22], poly(propylene) (PP) [23], poly(ethylene oxide (PEO) [24, 25], poly(acrylonitrile) 
(PAN) [24, 26], poly(vinylidene fluoride) and its copolymers (PVDF-TrFE and PVDFco-hexafluoropropene, PVDF-HFP) [27-30]. In order to improve the thermal and mechanical properties of porous polypropylene separators (PP) for lithium-ion batteries, a $\mathrm{SiO} 2$ layer has been placed in both sides of the separator, these layers improving the capacity and performance of this separator when compared to pristine PP separator [31]. The effect of temperature on the performance for macroporous separators based on polyethylene and polypropylene were investigated and these separators presented performance degradation when submitted to an aging treatment [32]. Further, electrospun nanofiber separators of organic F-doped poly-m-phenyleneisophthalamide have been proposed for lithium-ion batteries. This separator is characterized by lower electronic conductivity and higher electrochemical stability window when compared to commercial polyethylene membranes [33]. A new multifunctional separator based on poly(ethylenealternate-maleic acid) dilithium salt into a poly(vinylidene fluoridehexafluoropropylene) copolymer matrix has been developed showing improved battery performance due to $\mathrm{Mn}$ chelate ions [34]. PVDF and its copolymers belong to the fluorinated class and are characterized by exceptional properties for battery separator applications such as high polarity, excellent thermal and mechanical properties, wettability by organic solvents, being chemically inert and stable in cathodic environment and controllable porosity in binary and ternary systems $[35,36]$.

The advantages of the co-polymer PVDF-TrFE for battery separator applications with respect to PVDF and other copolymers are that the porous PVDF-TrFE membranes exhibit low degree of crystallinity, high contents of polar phase ( $\beta$-phase) and the possibility of controlling its porosity in binary systems at room temperature [37].

Microporous membranes based on PVDF-TrFE as battery separators have been prepared by thermal induced phase separation (TIPS) [30] and composite membranes have been developed with lithium salts [29] and fillers such as zeolite (NaY) [38], barium titanate $\left(\mathrm{BaTiO}_{3}\right)$ [39], carbon nanotube (CNT) [40], montmorillonite (MMT) [41]. It has been reported that that the membrane structure of PVDF-TrFE prepared by TIPS strongly depends on the solvent evaporation temperature on the polymer/solvent ratio. The porosity of membranes, ranging from 70 to $80 \%$, determines the electrolyte solution uptake, being larger (up to $600 \%$ ) for the samples with larger porosity. The electrolyte solution improves the ionic conductivity of the microporous membranes with the ionic conductivity decreasing with increasing degree of porosity of the membranes [28, 30]. For PVDF-TrFE composites, the optimized filler contents leading to membranes with 
better electrochemical performance have been shown to be $4 \mathrm{wt} \%$ of MMT, $16 \mathrm{wt} \%$ of $\mathrm{NaY}, 16 \mathrm{wt} \%$ of $\mathrm{BaTiO}_{3}$ with $500 \mathrm{~nm}$ average size and $0.1 \mathrm{wt} \%$ of MWCNT. Further, filler type deeply affects membrane separator performance in lithium-ion batteries [42]. Recently, it has been demonstrated that the best fluoropolymer-based separator membrane with degree of porosity larger than 50\% is PVDF-TrFE due to the higher $\beta$ phase content that facilitates faster lithium ion migration due to its higher polarity and electromechanical response with respect to other polymer phases [43]. On the other hand, typically obtained pore size obtained in PVDF-TrFE ranges from 2.5 to $4 \mu \mathrm{m}$, whereas the ideal pore size is below $1 \mu \mathrm{m}$ in order to avoid the trend for particle penetration within the separator and the formation of dendrites during excessive loading [44]. In order to improve those issues, the goal of the present work is to prepare porous membranes of PVDF-TrFE with pore size below $1 \mu \mathrm{m}$ with different degrees of porosity through a simple, reproducible and scalable method. For a given average pore size, the effect of degrees of porosity (ranging from $30 \%$ to $70 \%$ ) on the lithium ion battery cycling performance was evaluated. Based on the experimental results and theoretical simulations, the ideal degree of porosity should be above 50\% [45].

The porosity within PVDF-TrFE was obtained by using $\mathrm{ZnO}$ nanoparticles with sizes between 90-210 $\mathrm{nm}$. Moreover, the $\mathrm{ZnO}$ nanoparticles are low-cost, non-toxic and simple to remove from the polymer in acidic solution. Further, the fabrication method of this separator allows a suitable control of the degree of porosity and pore size and can be easily up-scaled for industrial production. Moreover, impressive electrochemical performance of the $\mathrm{Li} / \mathrm{C}-\mathrm{LiFePO} 4$ half-cells, make such mesoporous separator membranes a promising alternative to commercial LIBs separators.

\section{Experimental details}




\subsection{Materials}

Poly(vinylidene fluoride-trifluorethylene) (PVDF-TrFE) (70/30) and poly(vinylidene fluoride) (PVDF, Solef 5130) were purchased from Solvay.

Zinc oxide nanoparticles ( $\mathrm{ZnO}$, average particle size (APS): 90-210 nm) were acquired from Iolitec. C-LiFePO 4 (LFP) and carbon black (Super P-C45) were supplied by Phostech Lithium and Timcal Graphite \& Carbon, respectively.

The solvents N,N'-dimethylpropyleneurea (DMPU), N,N-dimethylformamide (DMF), the conventional electrolyte $1 \mathrm{M} \mathrm{LiPF}_{6}$ in ethylene carbonate-dimethyl carbonate (ECDMC, 1:1 vol) and the hydrochloric acid solution $(\mathrm{HCl})(37 \%)$ were purchased from LaborSpirit, Merck, Iolitec and Sigma-Aldrich, respectively

\subsection{Membrane preparation}

PVDF-TrFE composites were prepared following the general guidelines presented in [46]. First $\mathrm{ZnO}$ powder was dispersed in a solution of N,N-dimethylformamide (DMF) at a polymer plus $\mathrm{ZnO}$ concentration of $15 \%(\mathrm{w} / \mathrm{w})$ of the total solution with concentrations of $\mathrm{ZnO}$ relative to the polymer of $10 \%, 30 \%, 50 \%$ and $70 \%(\mathrm{w} / \mathrm{w})$. The processing steps and corresponding sequence are illustrated in Figure 1.

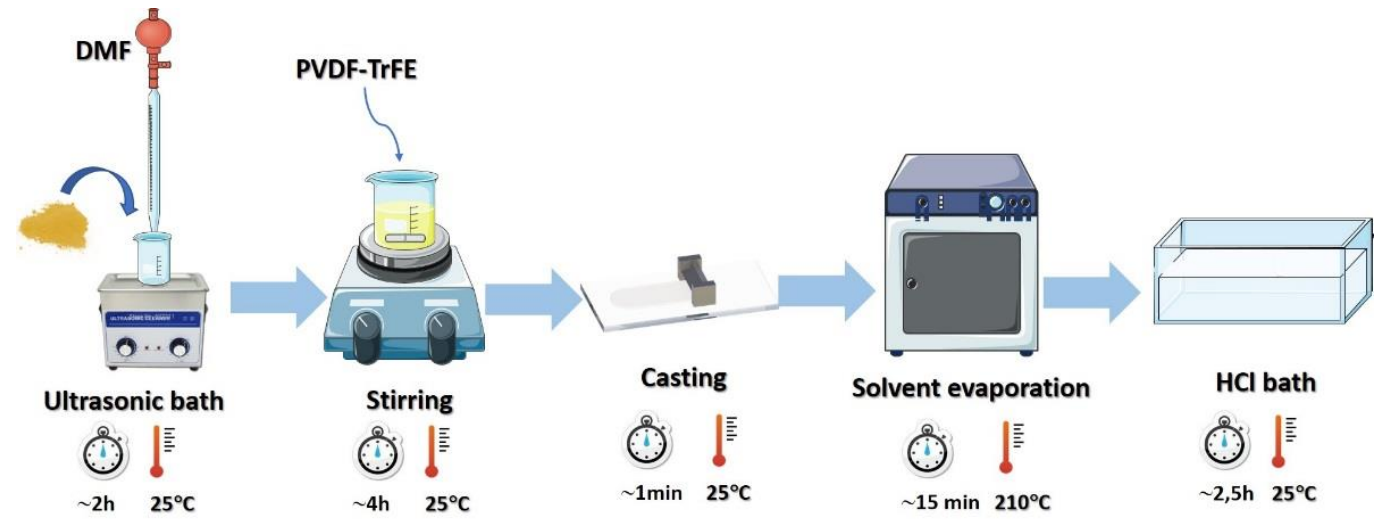

Figure 1 - Main experimental steps for the processing of PVDF-TrFE membranes.

The $\mathrm{ZnO}$ particles were dispersed in DMF with the help of an ultrasonic bath (Ultrasons Selecta P) during 2 hours. After complete dispersion of the $\mathrm{ZnO}$ particles, PVDF-TrFE powder was added and dissolved under magnetic agitation during $4 \mathrm{~h}$ at $25^{\circ} \mathrm{C}$. After dissolution of the polymer, the solution was casted uniformly on clean glass substrates by doctor blade and placed in an air oven (Binder, ED23) at $210^{\circ} \mathrm{C}$ during 15 minutes [46]. For the preparation of the membranes, the films were then immersed in a $37 \% \mathrm{HCl}$ 
solution for $\mathrm{ZnO}$ removal. After completely removal of $\mathrm{ZnO}$ particles, the films were washed with deionized water for several times and mesoporous PVDF-TrFE membranes were obtained with average thickness of $\sim 75 \mu \mathrm{m}$. Finally, PVDF-TrFE membranes will be identified henceforth by the initial amount of $\mathrm{ZnO}$ in the composites, which was later removed.

\subsection{Characterization techniques and procedures}

$\mathrm{UV}$-visible spectra of the $\mathrm{HCl}$ solution after removal of the $\mathrm{ZnO}$ particles was obtained using a UV-vis spectrophotometer (Jasco V-670 spectrophotometer) in the spectral range of 300 to $700 \mathrm{~nm}$.

Surface morphology of the membranes was evaluated by Scanning Electron Microscopy (SEM) using a FEI Nova 200 with an accelerating voltage of $5 \mathrm{kV}$. The membranes were previously coated with gold for $120 \mathrm{~s}$ under $<10^{-4}$ bar pressure and $10 \mathrm{~mA}$ current (Sputter coater SC7620, Quorum Technologies Ltd, UK).

The polymer phase of the obtained membranes was determined by Fourier transformed infrared spectroscopy (FTIR) using a Spectrum 100 set up, Perkin-Elmer, in the ATR mode over a range of $650-1750 \mathrm{~cm}^{-1}$ with a resolution of $4 \mathrm{~cm}^{-1}$. 64 scans were performed for each sample

The thermal properties of the membranes were determined by Differential scanning calorimetry (DSC). DSC was carried out in a Perkin-Elmer Pyris 1 DSC instrument in nitrogen atmosphere at the temperature range between 25 and $200{ }^{\circ} \mathrm{C}$ with a heating rate of $10{ }^{\circ} \mathrm{C} \cdot \mathrm{min}^{-1}$. All samples were measured in $40 \mu \mathrm{L}$ aluminium pans with perforated lids to allow the release and removal of decomposition products.

The degree of crystallinity ( $\Delta \mathrm{X}_{\text {cryst }}$ ) of the samples was calculated from the DSC scans using following equation:

$$
\Delta \mathrm{X}_{c}=\frac{\Delta H_{f}}{\Delta H_{100}}
$$

where $\Delta H_{f}$ is the melting enthalpy of the sample and $\Delta H_{100}\left(103.4 \mathrm{~J}_{\mathrm{g}} \mathrm{g}^{-1}\right)$ is the melting enthalpy for a $100 \%$ crystalline sample [47].

The stress-strain mechanical measurements were carried out in the tensile mode with a TST350 Linkam Scientific Instruments at room temperature and a strain rate of $15 \mathrm{~mm} / \mathrm{s}$.

\subsection{Degree of porosity, electrolyte uptake and ionic conductivity}


The porosity of the PVDF-TrFE membranes was calculated as:

$$
\text { Porosity }(\%)=\left(1-\frac{\rho_{a}}{\rho_{c}}\right) \times 100 \%
$$

where $\rho_{c}$ stands for bulk density of PVDF-TrFE/ZnO films calculated with $1.78 \mathrm{~g} \cdot \mathrm{cm}^{-3}$ as the density of PVDF [48] and $5.61 \mathrm{~g} \cdot \mathrm{cm}^{-3}$ as the density of $\mathrm{ZnO}$ [49]. $\rho_{a}$ is the membrane apparent density.

The uptake value was obtained by immersing the membranes into the electrolyte solution and applying the following equation:

$$
\text { uptake }=\frac{m_{i}-m_{0}}{m_{0}} \times 100
$$

where $m_{0}$ is the weight of the dry membrane and $m_{i}$ is the weight of the membrane after immersion in the electrolyte solution.

Impedance spectroscopy measurements were carried out for the different membranes after immersion in the electrolyte solution for 15 minutes. Measurements were performed in the frequency range between $500 \mathrm{mHz}$ and $65 \mathrm{kHz}$ in an AutolabPGSTAT-12 (Eco Chemie) equipment in the temperature range from 20 to $60^{\circ} \mathrm{C}$. A constant volume support equipped with gold blocking electrodes located within a Büchi TO 50 oven was used for the measurements. The ionic conductivity $\left(\sigma_{\mathrm{i}}\right)$, tortuosity $(\tau)$ and MacMullin number $\left(\mathrm{N}_{M}\right)$ of the membranes were calculated after the following equations, respectively:

$$
\begin{gathered}
\sigma_{i}=\frac{d}{R_{b} \cdot A} \\
\sigma_{i}=\sigma_{0} \frac{\varepsilon}{\tau^{2}} \\
N_{M}=\frac{\sigma_{0}}{\sigma_{i}}
\end{gathered}
$$

where $R_{b}$ is the bulk resistance, $d$ is the thickness, $A$ is the area of the sample, $\sigma_{0}$ is the conductivity of the pure liquid electrolyte, $\sigma_{\mathrm{i}}$ is the room temperature conductivity of the membrane plus the liquid electrolyte and $\varepsilon$ is the degree of porosity of the membrane. 


\subsection{Electrode fabrication and electrochemical performance evaluation}

\subsubsection{Cathode preparation}

The cathode was prepared using $80 \mathrm{wt} . \% \mathrm{C}-\mathrm{LiFePO}_{4}, 10 \mathrm{wt} . \%$ carbon black and 10wt.\% PVDF in $2.25 \mathrm{~mL}$ of DMPU for $1 \mathrm{~g}$ of solid material, following the procedure reported in [50]. The resulting slurry was then casted on aluminum foil by doctor-blade technique and dried at $100^{\circ} \mathrm{C}$ for $2 \mathrm{~h}$. The active mass loading was $\sim 1 \mathrm{mg} \cdot \mathrm{cm}^{-2}$.

\subsubsection{Half-cell preparation and electrochemical testing}

Li/C-LiFePO4 2016 coin-type half-cells were assembled in an argon-filled glove box where $\mathrm{O} 2$ and $\mathrm{H} 2 \mathrm{O}$ levels were kept bellow $0.1 \mathrm{ppm}$. The half-cells were prepared using the different PVDF-TrFE membranes as separators (14 $\mathrm{mm}$ diameter) soaked in the electrolyte solution. Metallic lithium (10 mm diameter) was used as anode and the $\mathrm{C}$ LiFePO4 based electrode as cathode (10 mm diameter). Charge-discharge tests were performed at room temperature in the voltage range $2.5 \mathrm{~V}$ to $4.2 \mathrm{~V}$ at current rates from C/5to 2C $(\mathrm{C}=170 \mathrm{mAg}-1)$ using a multichannel Maccor 4200 potentiostat. For each PVDF-TrFE separator, a minimum of 6 half cells were fabricated and tested. 


\section{Results and discussions}

\section{1. $\mathrm{ZnO}$ removal}

$\mathrm{ZnO}$ particles were used as sacrificial additives for the preparation of the PVDF-TrFE membranes after considering their advantages: low cost, non-toxicity and easy removal by acidic solution, whereas PVDF-TrFE shows excellent chemical stability against acid solutions $[51,52]$. After the membranes are formed, the $\mathrm{ZnO}$ particles are removed from the PVDF-TrFE membrane to give rise to a porous membrane structure and improve electrolyte uptake, ionic conductivity and electrochemical performance. In order to remove $\mathrm{ZnO}$ from the as-prepared PVDF-TrFE membranes, an $\mathrm{HCl}$ solution of $37 \%$ at room temperature was used and upon immersion into the $\mathrm{HCl}$ solution, the color of the membranes begins changed from slightly yellow to white.

In order to evaluate $\mathrm{ZnO}$ removal, the variations in membrane's weight were recorded as a function of time, as shown in Figure 2a). Figure 2a) shows that pristine PVDF-TrFE does not undergo any weight loss, proving that the $\mathrm{HCl}$ solution does not affect the weight and, therefore, PVDF-TrFE is chemically stable in $\mathrm{HCl}$ solution. For the PVDF$\mathrm{TrFE} / \mathrm{ZnO}$ composite membranes, the weight loss increases with increasing $\mathrm{ZnO}$ particle concentration and effectively demonstrates the removal of the $\mathrm{ZnO}$ filler from the composite.
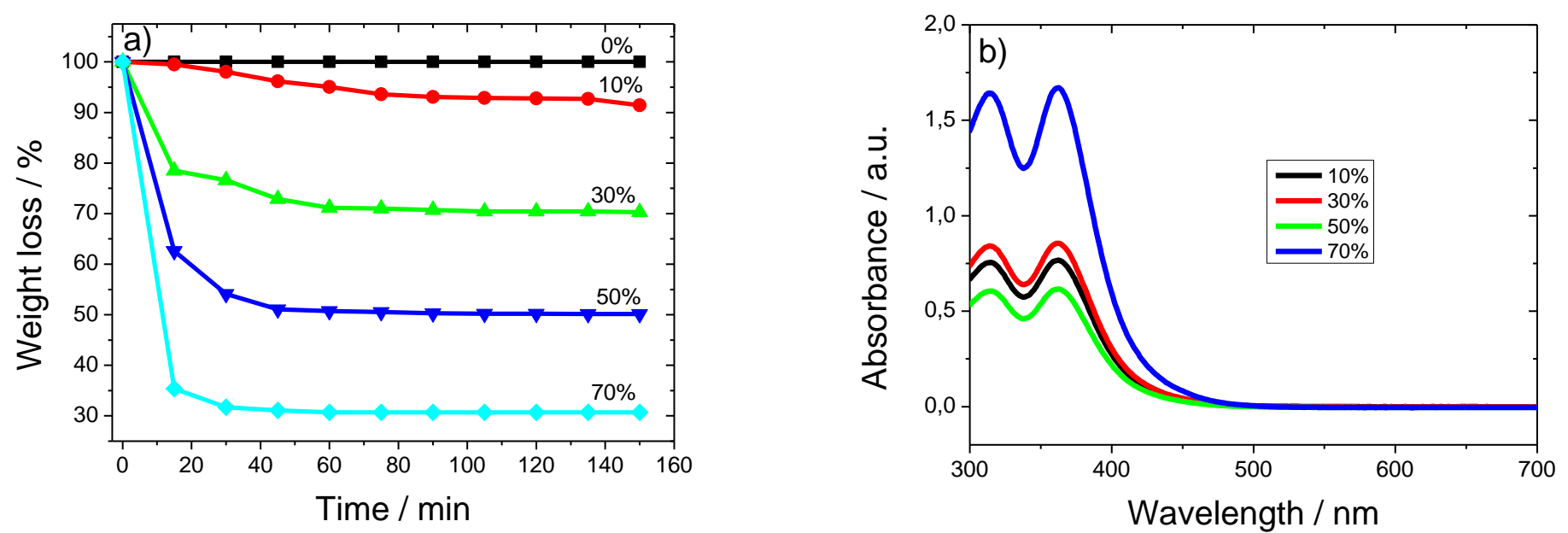

Figure 2 - Weight loss as a function of time for the PVDF-TrFE membranes with different $\mathrm{wt} \%$ of $\mathrm{ZnO}$ (a). UV-visible spectra of the $\mathrm{HCl}$ solution after $\mathrm{ZnO}$ particle removal from the composite (b). 
Figure $2 \mathrm{a}$ also shows that for the PVDF-TrFE membranes with $\mathrm{ZnO}$ concentration above of $30 \% \mathrm{wt}$, the membrane weight is reduced by more than half of the expected weight loss (original $\mathrm{ZnO}$ concentration) after $15 \mathrm{~min}$ in the solution and the weight reaches a steady state after $2 \mathrm{~h}$, indicating the complete removal of the $\mathrm{ZnO}$.

After $\mathrm{ZnO}$ particles dissolution, the color of the $\mathrm{HCl}$ solution changes to yellow. The $\mathrm{UV}-$ Visible spectra of the $\mathrm{HCl}$ solution is presented in figure $2 \mathrm{~b}$, where the two vibration peaks at $320-380 \mathrm{~nm}$, characteristic of the UV - Vis spectrum of $\mathrm{ZnO}$ particles [53], demonstrate the presence of the dissolved $\mathrm{ZnO}$ in the solution. Further, the vibration peaks wavelength is independent of the $\mathrm{ZnO}$ concentration but are more intense for higher $\mathrm{ZnO}$ concentration (figure $2 \mathrm{~b}$ )). Thus, the present method shows to be efficient in the development of mesoporous membranes with controlled porosity, as it will be shown in the following section.

3.2.Membrane morphology, polymer phase, thermal, mechanical properties and degree of porosity

$\mathrm{ZnO}$ removal from the composite leads to porous membranes as demonstrated by the surface SEM presented in Figure 3.

The SEM images of figure $3 \mathrm{a}$ and $3 \mathrm{~b}$ represent the morphology of pristine PVDF-TrFE and PVDF-TrFE composite with 50wt.\% of $\mathrm{ZnO}$, respectively. The images in figure 3c and $3 \mathrm{~d}$ illustrate the morphology of the PVDF-TrFE membranes after the removal of $\mathrm{ZnO}$ in the samples with $50 \mathrm{wt} . \%$ and $70 \mathrm{wt} \%$ filler content, respectively. The presented images are representative for the rest of the samples. Figure $3 \mathrm{a}$ and $\mathrm{b}$ show that the samples show the characteristic compact fibrillary microstructure of PVDF-TrFE [54], independently on the filler content. Further, figure $3 \mathrm{~b}$ also shows that the $\mathrm{ZnO}$ particles are well dispersed and distributed in the PVDF-TrFE polymer matrix. 

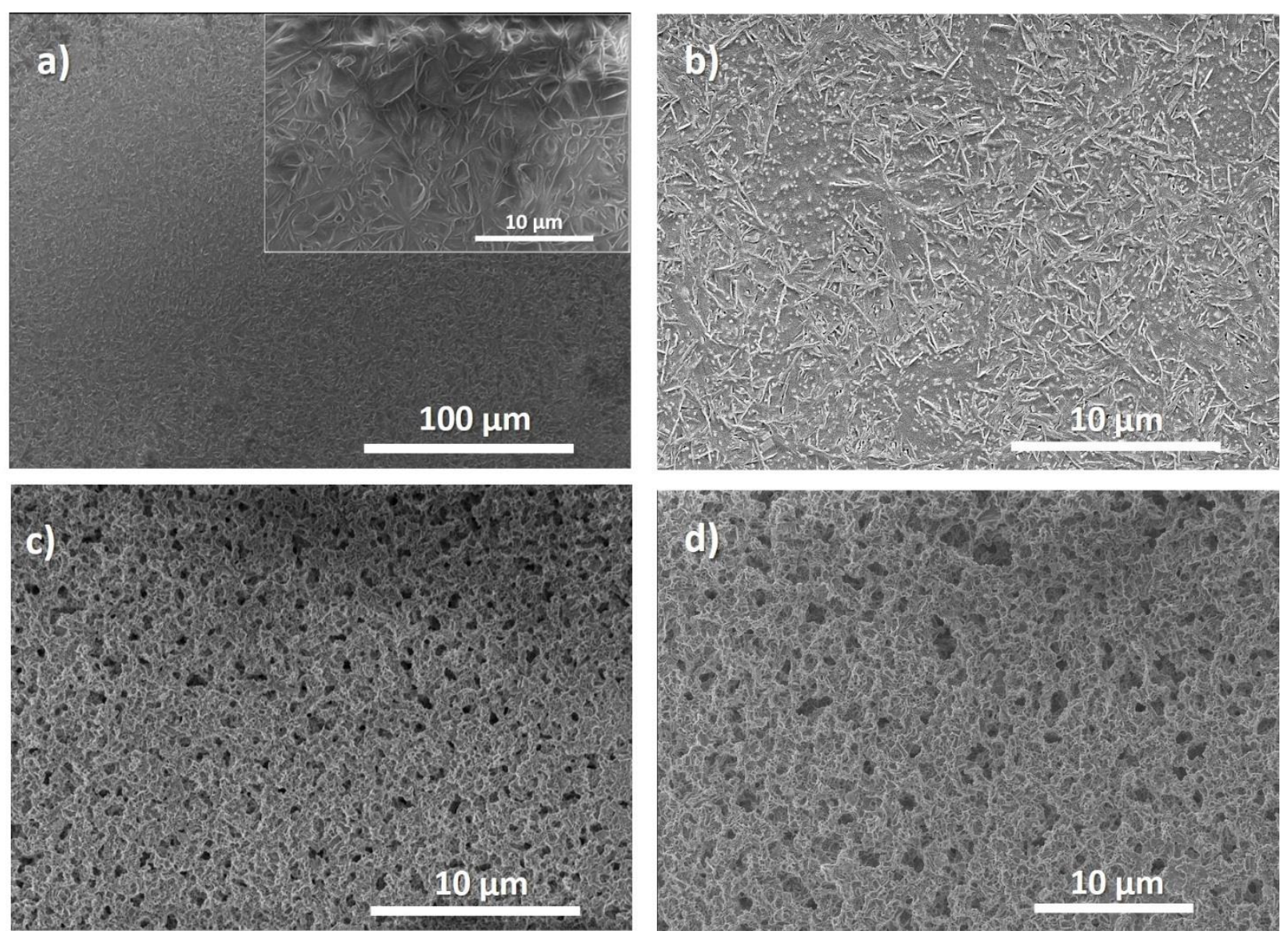

Figure 3 - Surface SEM images of pristine PVDF-TrFE a); PVDF-TrFE with 50wt.\% of $\mathrm{ZnO}$ b); PVDF-TrFE after 50\%wt ZnO particles removal (c); and PVDF-TrFE after $70 \%$ wt $\mathrm{ZnO}$ particles removal (d).

After $\mathrm{ZnO}$ removal (figures $3 \mathrm{c}$ and $\mathrm{d}$ ) an interconnected porous structure is obtained in PVDF-TrFE membrane, the pore sizes being consistent with $\mathrm{ZnO}$ particles size. The pores are well distributed along the membrane and their quantity increases with increasing initial $\mathrm{ZnO}$ content in the composite. It is to notice that an interconnected porous structure is essential for uptake of the electrolyte solution for battery applications.

Fourier transform infrared spectroscopy (FTIR) allows to determine whether $\mathrm{ZnO}$ removal affects the vibration spectra of PVDF-TrFE polymer (figure 4a). The FTIR spectra of PVDF-TrFE is characterized by the vibration bands at 844, 880, 1402 and 1432 $\mathrm{cm}^{-1}$ identified in figure $4 \mathrm{a}$ ) and corresponding to the of $\mathrm{CF}_{2}$ symmetric stretching or $\mathrm{CF}_{2}$ rocking, $\mathrm{CH}_{2}$ wagging and $\mathrm{CH}_{2}$ bending, respectively [55]. These vibration peaks do not suffer any variation in the different PVDF-TrFE membranes, indicating that the removal of $\mathrm{ZnO}$ does not change the crystal phase of PVDF-TrFE (figure 4a). 
The characterization of the mechanical behavior of the membranes is relevant in order to apply them as lithium-ion battery separators, since their integrity is necessary to obtain excellent cycling performance [56].

The stress-strain characteristic curves of the PVDF-TrFE membranes obtained after $\mathrm{ZnO}$ removal are shown in figure $4 b)$.

It is observed that the porosity present in the different membranes determines the overall mechanical properties of the membranes, leading to a decrease of the Young modulus with increasing porosity, i.e. $\mathrm{ZnO}$ concentration in the composite (figure $4 \mathrm{~b}$ ).

With respect to the final stress and strain, they are the lowest for the PVDF-TrFE membrane prepared after $50 \mathrm{wt} . \%$ of $\mathrm{ZnO}$ removal, which may be related to poor pore interconnectivity, when compared to the remainder membranes.

Considering that the mechanical properties of the separator are essential to obtain excellent cyclability [56] and taking into account the results of figure 4b), the mechanical properties of the PVDF-TrFE membranes decrease with the presence of the pores (e.g. decrease of the final stress-strain). In any case, all membranes show mechanical integrity for being used as separator membranes for lithium ion battery applications.

The DSC thermograms of the different membranes are shown in figure $4 c$ ) and are all characterized by two endothermic peaks: one at $105{ }^{\circ} \mathrm{C}$, that corresponds to the ferroelectric-paraelectric phase transition (Curie transition), and other at $150{ }^{\circ} \mathrm{C}$, corresponding to the melting of PVDF-TrFE [57].

The area of the melting peak allows to calculate the degree of crystallinity [54], which is the same $(\sim 28 \%)$ for all membranes, independently of the initial $\mathrm{ZnO}$ concentration.

The low value of the degree of crystallinity is appropriate for battery separator applications, since ion transport occurs in the amorphous region of the membrane, as well as the electrolyte uptake [58]. 

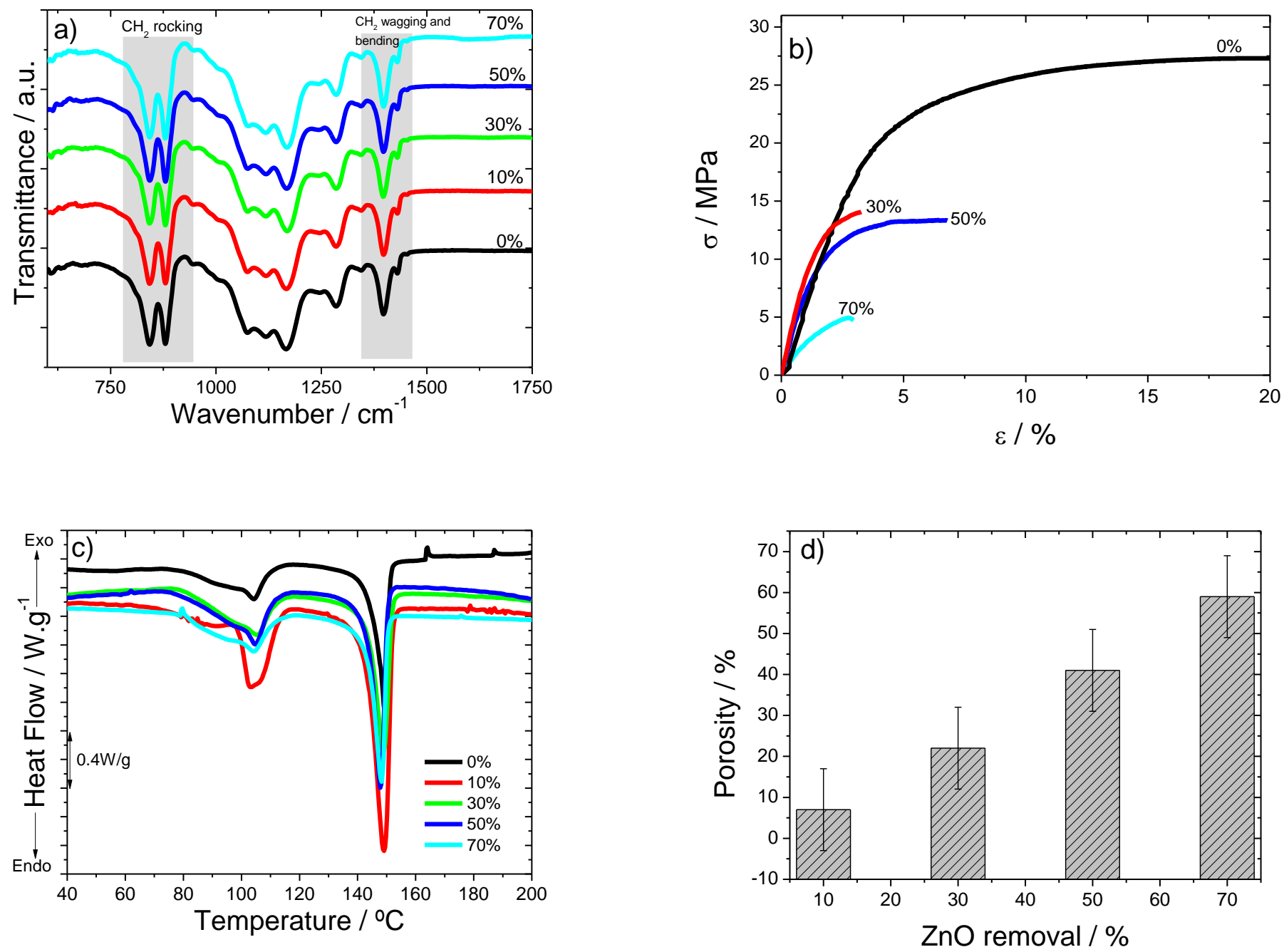

Figure 4 - FTIR-ATR spectra (a), Stress-strain curves (b), DSC curves (c), and Degree of porosity (d) for all PVDF-TrFE membranes.

Figure $4 \mathrm{~d}$ ) shows the degree of porosity calculated using equation 2 as a function of $\mathrm{ZnO}$ removal. It is observed that the degree of porosity of the PVDF-TrFE membranes is proportional to the $\mathrm{ZnO}$ removal within the experimental error and that a maximum degree of porosity of $\sim 60 \%$ is obtained for the sample obtained after $70 \% \mathrm{ZnO}$ removal. 
Thermal shrinkage analysis is extremely important as it affects battery safety and mitigates thermal damage in lithium-ion batteries [59]. Figure 5 shows the photographs of membranes prepared after $70 \mathrm{wt}$. $\% \mathrm{ZnO}$ removal with no thermal treatment and after thermal treatments at $50{ }^{\circ} \mathrm{C}$ and $100{ }^{\circ} \mathrm{C}$ for $\mathrm{xxx}$ minutes.
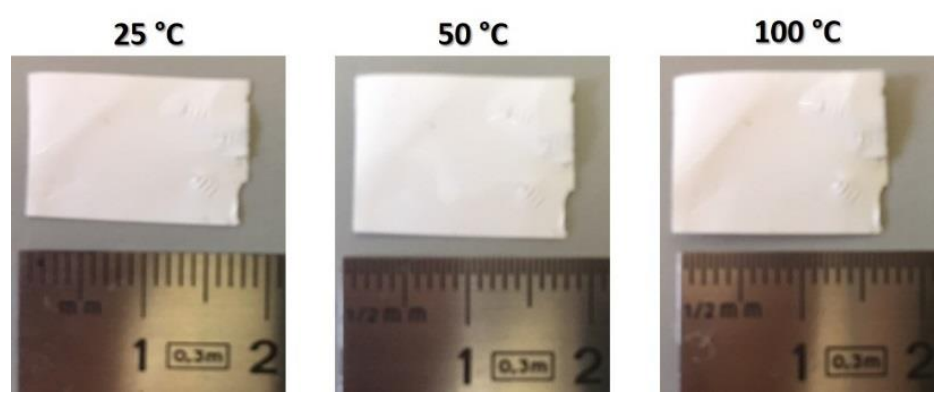

Figure 5 - Photographs of PVDF-TrFE separators before and after different thermal treatments at 50 and $100{ }^{\circ} \mathrm{C}$ for XXX minutes.

As it is demonstrated in figure 5, the developed PVDF-TrFE membranes exhibit excellent thermal stability: after thermal treatment at $100{ }^{\circ} \mathrm{C}$, the size of the membrane is the same as for the as prepared membranes at $25^{\circ} \mathrm{C}$. For the rest of the PVDF-TrFE membranes, the same behavior is obtained.

For fluorinated membranes, the uptake of the electrolyte solution depends on the relative proportion of pores within the membranes [58] and, therefore uptake has been just evaluated for PVDF-TrFE membranes with degree of porosity above of $\sim 7 \%$. The uptake of the PVDF-TrFE membranes is reported in figure 6a) as a function of the dipping time. Uptake is determined by swelling of the amorphous regions of the polymer to accommodate the electrolyte [60]. 

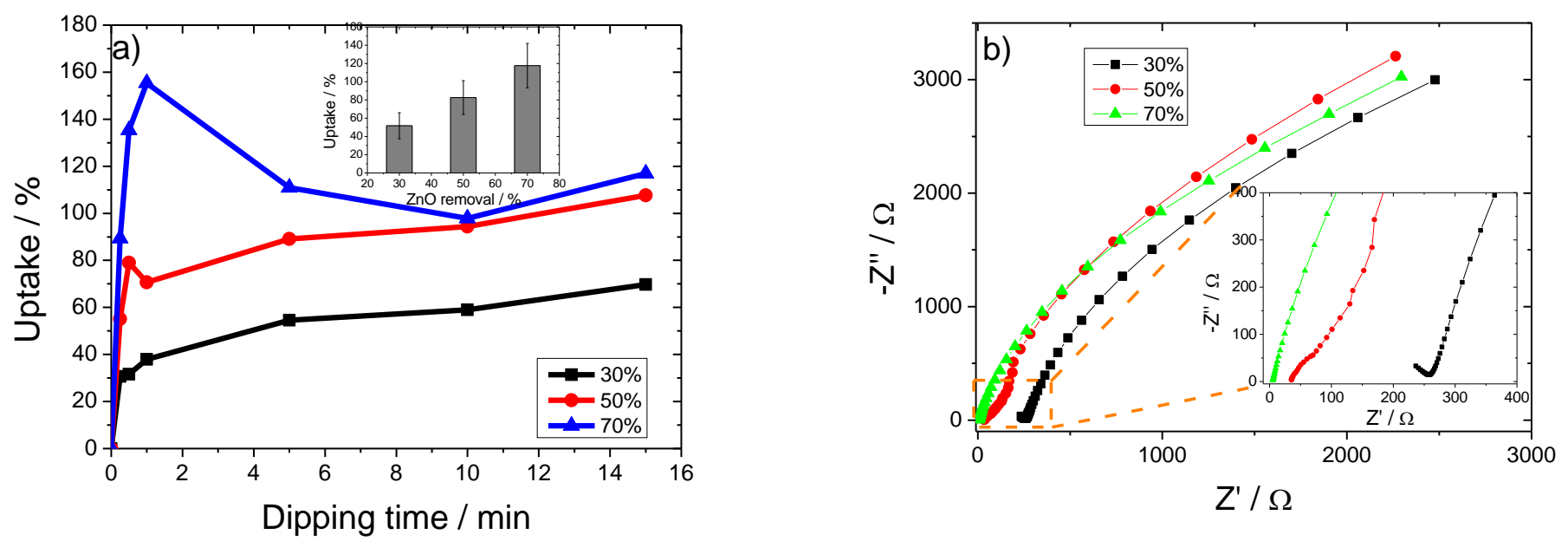

Figure 6 - Uptake value (a) and Nyquist plots (b) at room temperature for different PVDF-TrFE membranes.

For all PVDF-TrFE membranes, saturation is obtained approximately after 5 minutes of immersion and the maximum uptake value for the membranes increase with increasing porosity (insert in figure 6a).

The uptake behavior is a result of the porosity and the gelation of PVDF-TrFE with the electrolyte, which results from the electrostatic interaction between the solvents and the surface polar $-\mathrm{C}-\mathrm{F}$ groups of the polymer [61].

The ionic conductivity of the membranes was determined by impedance spectroscopy at $25^{\circ} \mathrm{C}$, the corresponding Nyquist plots are presented in figure $6 \mathrm{~b}$ ). The Nyquist plots of all membranes show an inclined straight-line (typical of the blocking electrode capacitive behavior) whose intercept with the real axes, Z', provides the ionic resistance of the PVDF-TrFE membrane [62] which can be used to calculate the ionic conductivity through the equation 4 . The obtained value of the ionic conductivity is presented in Table 1.

Table 1 shows that the different PVDF-TrFE membranes show a high ionic conductivity with a value proportional to the degree of porosity and, therefore, to the electrolyte uptake. Thus, the highest ionic conductivity value of $1.6 \mathrm{mS} / \mathrm{cm}$ is found for the PVDF-TrFE membrane after $70 \mathrm{wt} . \%$ of $\mathrm{ZnO}$ removal, but all membranes show ionic conductivity values above $>10^{-4} \mathrm{~S} / \mathrm{cm}$, being therefore adequate for lithium-ion battery separator membranes [63].

Another relevant parameters for separator membranes such as tortuosity and Macmullin number were calculated for the PVDF-TrFE membranes using equations 5 and 6 and the corresponding values are presented in Table 1. 
Table 1 - Room temperature ionic conductivity ( $\sigma \mathrm{i})$, tortuosity $(\tau)$, and MacMullin number $\left(\mathrm{N}_{\mathrm{M}}\right)$ for the different PVDF-TrFE membranes

\begin{tabular}{|c|c|c|c|}
\hline Sample & $\boldsymbol{\sigma}_{\mathbf{i}} / \mathbf{\pm \mathbf { 0 . 3 }} \mathbf{\text { mS.cm}}$ & $\mathbf{\tau} \mathbf{\mathbf { 2 }}$ & $\mathbf{N}_{\mathbf{M}} \mathbf{\pm \mathbf { 5 }}$ \\
\hline 30 wt.\% & 0.1 & 5 & 94 \\
\hline 50 wt.\% & 0.6 & 3 & 21 \\
\hline 70 wt.\% & 1.6 & 2 & 7 \\
\hline
\end{tabular}

The tortuosity $(\tau)$ describes the ionic transport path due to the porous structure with respect to a straight line $d$ and the MacMullin number $\left(\mathrm{N}_{M}\right)$ describes the influence of the porous microstructure of the separators on the electrochemical performance of the lithium ion battery [64], the value of both parameter (ideal values of 1) will decrease with the increase in degree of porosity and increase in electrolyte uptake. The obtained values are similar to those found for commercial separators [64], indicating these porous PVDFTrFE membranes could be a promising alternative candidate as battery separator.

\subsection{Battery performance}

The electrochemical performance of the PVDF-TrFE membrane electrolytes was investigated in $\mathrm{Li} / \mathrm{C}-\mathrm{LiFePO}_{4}$ half-cells. $\mathrm{LiFePO}_{4}$ represents one of most promising cathode active materials for the next generation lithium-ion batteries in transportation applications $[65,66]$. Figure 7a) shows the charge-discharge voltage profiles of the Li/C$\mathrm{LiFePO}_{4}$ half-cells in the potential window of 2.5 and $4.2 \mathrm{~V}$ at different C-rates $(\mathrm{C} / 10$ to 2C) using PVDF-TrFE membranes prepared after $70 \mathrm{wt} \% \mathrm{ZnO}$ removal as the separator. For other PVDF-TrFE membranes (presented in Table 1), the cycling behavior as a function of C-rate is similar to that reported in the figure 7a). For the corresponding charge-discharge profile for 5th cycle at each C-rate is presented in figure $7 \mathrm{a}$ ), where in all case the typical flat voltage profiles are observed at around 3.3-3.5 V. This voltage profile corresponds to the presence of a two-phase coexistence reaction for $\mathrm{LiFePO}_{4}$ cathode $\left(\mathrm{Fe}^{2+} / \mathrm{Fe}^{3+}\right.$ redox reaction between $\mathrm{FePO}_{4}$ and $\left.\mathrm{LiFePO}_{4}\right)$ [67] and is independent 
of the cycle number and C-rate. On the other hand, an oblique line is observed for high C-rate (2C), that demonstrates the capacitive behavior [68].

In addition, figure 7a) shows that the difference between charge and discharge potentials is higher when the C-rate increases, $\sim 0.6 \mathrm{~V}$ due to the polarization caused by lower transference number of $\mathrm{Li}^{+}$ions also on the interfacial reaction resistance on the lithium electrode [69].

For the PVDF-TrFE membrane prepared after $70 \mathrm{wt} \% \mathrm{ZnO}$ removal the discharge capacity values are $137 \mathrm{mAh} . \mathrm{g}^{-1}, 134 \mathrm{mAh} . \mathrm{g}^{-1}, 127 \mathrm{mAh} . \mathrm{g}^{-1}, 116 \mathrm{mAh} . \mathrm{g}^{-1}$ and $108 \mathrm{mAh} . \mathrm{g}^{-}$ ${ }^{1}$ at the $\mathrm{C}$-rates of $\mathrm{C} / 10, \mathrm{C} / 5, \mathrm{C} / 2, \mathrm{C}$ and $2 \mathrm{C}$, respectively, which corresponds to $80 \%$, $79 \%, 75 \%, 68 \%$ and $64 \%$ of the theoretical capacity of $\mathrm{C}-\mathrm{LiFePO}_{4}\left(170 \mathrm{mAh} . \mathrm{g}^{-1}\right)$, indicating an excellent electrochemical behavior. This excellent electrochemical behavior is due to the high ionic conductivity of the PVDF-TrFE separator membrane.

Figure $7 \mathrm{~b}$ represents the fifth charge-discharge curve at $2 \mathrm{C}$-rate for the different PVDFTrFE membranes, where the discharge capacities are $108 \mathrm{mAh} \cdot \mathrm{g}^{-1}, 87 \mathrm{mAh} \cdot \mathrm{g}^{-1}$, and 79 mAh.g ${ }^{-1}$ for the PVDF-TrFE membranes after 70wt.\%, 30wt.\% and 50wt.\% $\mathrm{ZnO}$ removal, respectively, showing that the behavior depends on the ionic conductivity (table 1) and mechanical stability of the membranes (figure $4 b$ ).

For the PVDF-TrFE membranes prepared after $30 \mathrm{wt} . \%$ and $50 \mathrm{wt} . \% \mathrm{ZnO}$ removal, the ionic conductivity value of both samples are similar within experimental error, the best battery performance being for the PVDF-TrFE membrane after $30 \mathrm{wt}$ \% $\mathrm{ZnO}$ removal due to the better mechanical properties of this membrane when compared to the PVDFTrFE membrane prepared after $50 \mathrm{wt} . \% \mathrm{ZnO}$ removal, which can lead to failure strain [56] and consequently lower cycling performance.

In relation to the PVDF-TrFE membrane prepared after $70 \mathrm{wt}$ \% $\mathrm{ZnO}$ removal, the higher charge-discharge behavior compared to the other membranes is due to the higher ionic conductivity value. Despite the lower mechanical properties of this membranes in comparison with the other two, the higher ionic conductivity value leads to obtain excellent cycling performance and demonstrated that the mechanical properties are good enough for separator applications. 

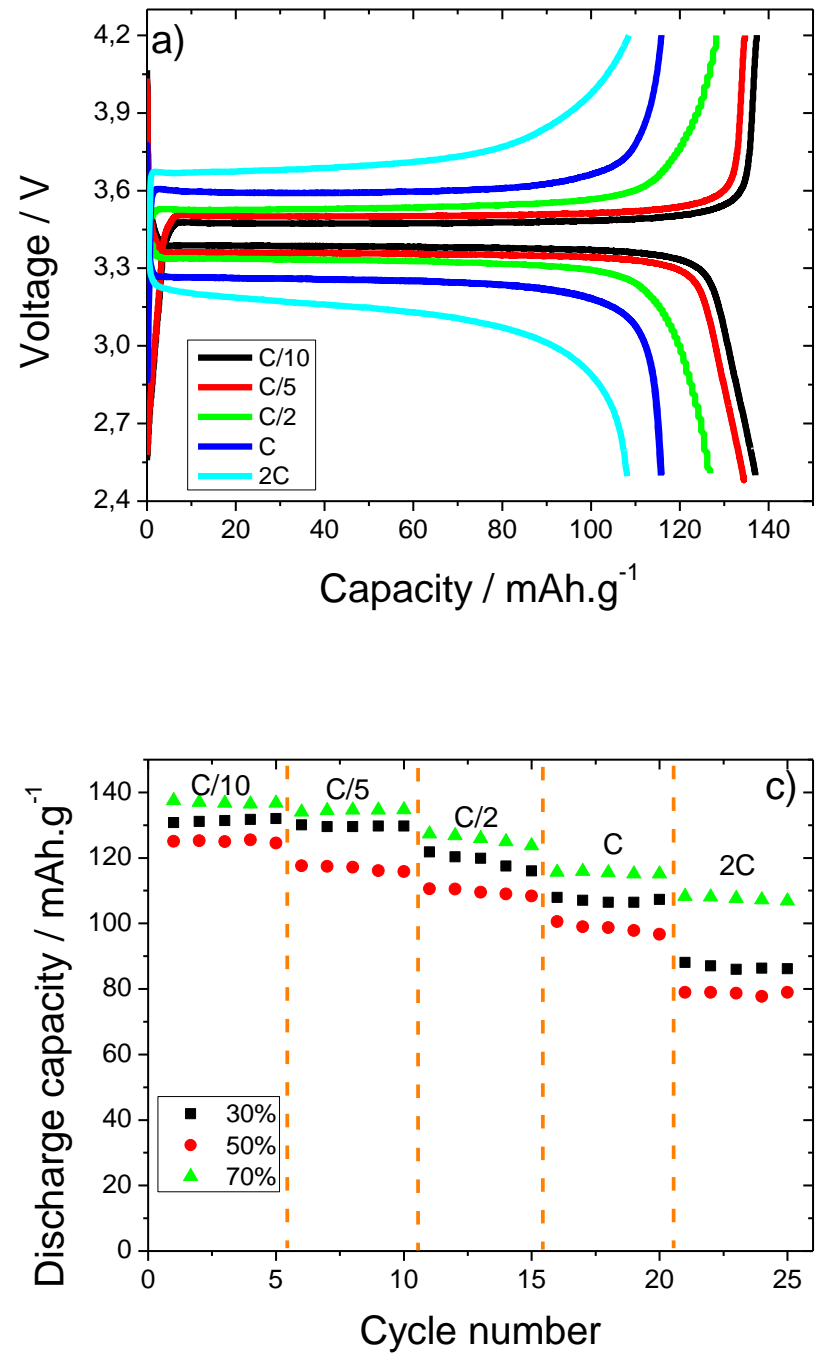
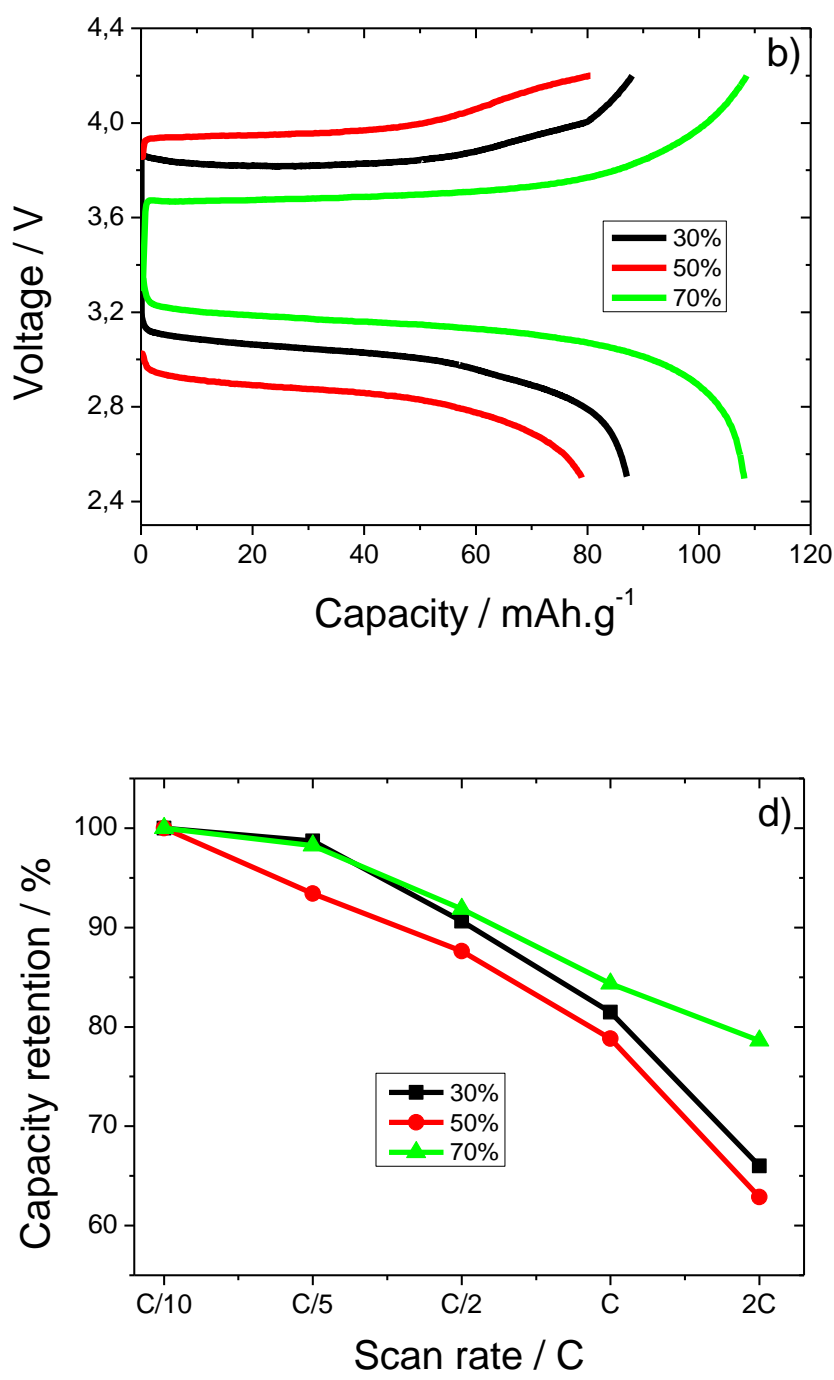

Figure 7 - 5th charge and discharge cycle room temperature profiles at rates from $\mathrm{C} / 10$ to $2 \mathrm{C}$ (a) for the membrane prepared after $70 \mathrm{wt} . \% \mathrm{ZnO}$ removal. Charge and discharge profiles at $2 \mathrm{C}$ for $5^{\text {th }}$ cycle for different PVDF-TrFE membranes (b). Rate performance as a function of the cycle number (c) and capacity retention at different C-rates (d) for different PVDF-TrFE membranes.

Figure 7c shows the discharge capacity as a function of cycle number for different PVDFTrFE membranes. Regardless of the C-rate, the discharge capacity is very stable as a function of the cycle number and the PVDF-TrFE membrane with the lowest cycle performance is the PVDF-TrFE membrane prepared after $50 \mathrm{wt} . \% \mathrm{ZnO}$ removal. The observed differences in cycling performance for the PVDF-TrFE membranes are basically due to two main factors: the ionic conductivity value and the mechanical properties. The difference between the PVDF-TrFE membranes prepared after $30 \mathrm{wt} . \%$ 
and $50 \mathrm{wt} . \% \mathrm{ZnO}$ removal are mainly due to the mechanical properties since the ionic conductivity values are similar, as well as the degree of crystallinity. For the PVDF-TrFE membrane prepared after $70 \mathrm{wt} . \% \mathrm{ZnO}$ removal, the highest cycle performance is due to the high ionic conductivity value, showing also that the mechanical properties are good enough for battery applications.

Figure 7d shows the charge capacity retention for the different $\mathrm{C}$-rates calculated through the normalization of the delivered capacity for each scan rate with respect to the nominal value for $\mathrm{C} / 10$ rate for the different membranes. Independently of the PVDF-TrFE membrane, it is observed that the capacity retention decreases with increasing C-rate, due to the diffusion phenomena taking place within the electrode active material phase [70]. This decrease in capacity retention is higher for membranes with low ionic conductivity (30 wt.\% and $50 \mathrm{wt} . \%$ of $\mathrm{ZnO}$ removal). The best capacity retention at $2 \mathrm{C}$ observed for the PVDF-TrFE membrane with $70 \mathrm{wt} \% \mathrm{ZnO}$ removal, leading to excellent cycling behavior. Given the good rate capability of all PVDF-TrFE membranes with different degrees of porosity (figure 7), Figure 8 shows the cycle stability at C/5 (figure 8a) and $2 \mathrm{C}$-rate (figure $8 \mathrm{~b}$ ) for 50 cycles.

For C/5-rate (figure 8a), good stability is observed with high discharge capacity values over 50 cycles for all PVDF-TrFE membranes. The differences observed in the discharge capacity value between the PVDF-TrFE membranes are due to the interplay of both factors: the ionic conductivity value and the mechanical properties of the PVDF-TrFE membranes.
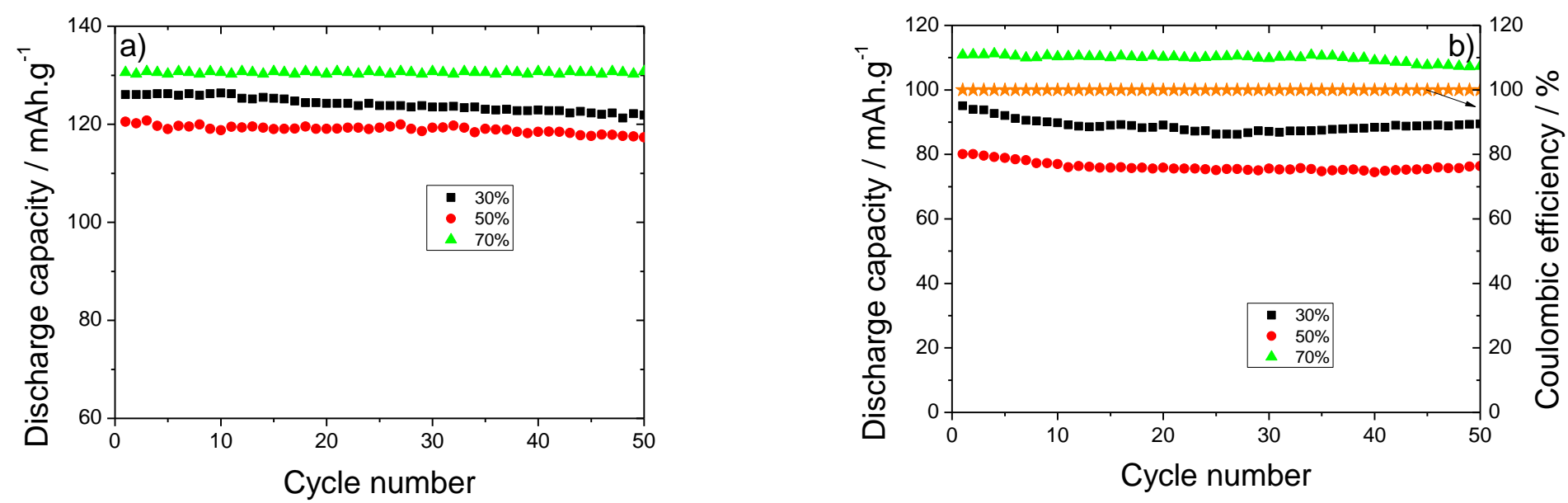

Figure 8 - Cycling performance of the PVDF-TrFE membranes when cycled at C/5 (a) and $2 \mathrm{C}(\mathrm{b})$. 
In relation to $2 \mathrm{C}$-rate (figure $8 \mathrm{~b}$ ), the battery performance for all PVDF-TrFE membranes is practically constant as a function of the number of cycles, with a capacity fade lower than $1 \%$, the best cycling performance being observed for PVDF-TrFE membrane prepared after $70 \mathrm{wt} . \% \mathrm{ZnO}$ removal, due to the larger ionic conductivity. The coulombic efficiency shown in figure $8 b$ is $\sim 100 \%$ for all PVDF-TrFE membranes regardless of the number of cycles, showing the reversibility of the process.

Considering the excellent charge-discharge results presented in figures 7 and 8 , table 2 compares the electrochemical properties of PVDF and copolymer separator membranes with pore sizes below $4 \mu \mathrm{m}$ and degree of porosity above $50 \%$ and soaked with the electrolyte solution. The selected membranes from the literature also use same electrode. Table 2 shows that the electrochemical results of our present work even at high C-rates are similar or even superior in comparison to other recent reported results for PVDF based separator membranes.

Table 2 - Electrochemical parameters for different PVDF and copolymers separator membranes.

\begin{tabular}{|c|c|c|c|c|c|}
\hline Polymer & Pore size / $\mu \mathrm{m}$ & Porosity / \% & $\sigma_{\mathrm{i}} / \mathrm{mS} \mathrm{cm}$ & Capacity/mAh.g ${ }^{-1}$ & Ref \\
\hline PVDF & $\sim 0.72-1.1$ & 78.9 & 1.72 & 110.3@5C (after 10 cycles) & [71] \\
\hline PVDF & $<1$ & 20 & 0.23 & 56@2C (after 50 cycles) & [72] \\
\hline PVDF-HFP & $<1$ & 70 & 3.2 & $\begin{array}{ll}---- \\
-1\end{array}$ & [73] \\
\hline PVDF-HFP & 0.8 & 78 & 1.03 & $145 @ \mathrm{C} / 2$ (after 50 cycles) & [74] \\
\hline PVDF-CTFE & 2 & 60 & 1.5 & 92@2C (after 50 cycles) & {$[75]$} \\
\hline PVDF-CTFE & $0.043-0.1$ & 74 & 0.8 & 89@8C (after 5 cycles) & [76] \\
\hline PVDF-TrFE & $2.5-4$ & 72 & 1.1 & 87@2C (after 50 cycles) & {$[43]$} \\
\hline PVDF-TrFE & $<1$ & 70 & 1.6 & 107@2C (after 50 cycles) & This work \\
\hline
\end{tabular}

Thus, considering the electrochemical results from figure 7 and 8 and table 2, PVDFTrFE membranes prepared after removal of $70 \mathrm{wt} . \%$ of $\mathrm{ZnO}$ are excellent for lithium-ion battery applications. 
As a proof of concept, a full cell battery was fabricated. The anode electrode was produce by the procedure presented in [50] with the following slurry composition: graphite powder, Super P carbon and PVDF binder with a ratio of 80:10:10. Electrochemical impedance spectroscopy (EIS) was carried out in the frequency range from $10 \mathrm{~Hz}$ to 10 KHz. Figure 9 shows the impedance spectra for the full cell battery with the PVDF-TrFE separators developed in this work.

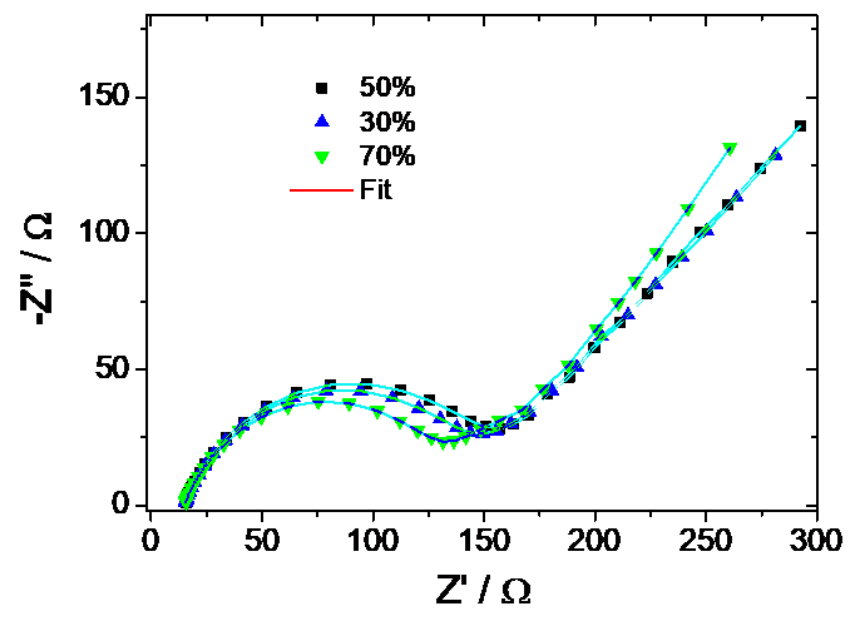

Figure 9 - Impedance spectra for the full batteries prepared with the PVDF-TrFE separator membranes.

The Nyquist plots presented in figure 9 are characterized by a semicircle (overall resistance, which is the sum of the ohmic resistance, that represents the contact film resistance, and resistance contributions from the charge-transfer reaction) in the high and medium frequency regions and a straight line that is associated to the $\mathrm{Li}^{+}$diffusion process in the low frequency regions [50]. For the batteries prepared with the different PVDFTrFE membranes, the overall resistance is below $200 \Omega$, which demonstrates the good compatibility with both electrodes.

The separator membrane presented in this work represents a novel separator for this application with controlled porosity after a simple and reproductible production method. 


\section{Conclusions}

Mesoporous membranes of poly(vinylidene fluoride-co-trifluoroethylene) with controlled porosity were prepared through $\mathrm{ZnO}$ particle removal from the polymer matrix. The membranes were prepared with different $\mathrm{ZnO}$ initial contents between 10wt.\% and 70 wt.\%. The $\mathrm{ZnO}$ removal from the PVDF-TrFE membranes is fast and efficient and the $\mathrm{ZnO}$ removal originated the porosity of the PVDF-TrFE matrix. The morphology, mechanical properties, uptake value and ionic conductivity value of the membranes depend on the final porosity of the membrane but the thermal properties (melting behavior), degree of crystallinity and polymer phase are independent on the membranes preparation procedure.

The PVDF-TrFE membrane after removal $70 \mathrm{wt} . \%$ of $\mathrm{ZnO}$ show the best ionic conductivity value of $1.6 \mathrm{mS} . \mathrm{cm}^{-1}$, a tortuosity and Macmullin values of 2.3 and 7.3, respectively, and suitable mechanical properties. Further, those membranes lead to excellent electrochemical performance of $\mathrm{Li} / \mathrm{C}$ - $\mathrm{LiFePO}_{4}$ half-cells up to $\mathrm{C}$-rates of $1 \mathrm{C}$, the discharge capacity being between $137 \mathrm{mAh} \cdot \mathrm{g}^{-1}$ at $\mathrm{C} / 10$ and $108 \mathrm{mAh} . \mathrm{g}-1$ at 2C. Further, a high capacity retention of $79 \%$ at $2 \mathrm{C}$ it is observed. The suitable performance of the developed separators is also demonstrated in full battery cells.

Thus, it is concluded that the separators developed in this work and prepared after a simple and reproducible method, allowing control of overall porosity and pore size, are suitable for high performance lithium-ion battery applications.

\section{Acknowledgments}

The authors thank the FCT (Fundação para a Ciência e Tecnologia) for financial support under the framework of Strategic Funding grants UID/FIS/04650/2013, UID/EEA/04436/2013 and UID/QUI/0686/2016; and projects no. POCI-01-0145- 
FEDER-028157 and POCI-01-0145-FEDER-028237. The authors also thank the FCT for financial support under grant SFRH/BPD/112547/2015 (C.M.C.). J.N.P. wish to thank the financial support of the project Centro-01-0145-FEDER-000017 - EMaDeS - Energy, Materials and Sustainable Development, co-financed by the Portugal 2020 Program (PT 2020), within the Regional Operational Program of the Center (CENTRO 2020) and the European Union through the European Regional Development Fund (ERDF). Financial support from the Spanish Ministry of Economy and Competitiveness (MINECO) through project MAT2016-76039-C4-3-R (AEI/FEDER, UE) (including FEDER financial support) and from the Basque Government Industry Department under the ELKARTEK and HAZITEK Program is also acknowledged

\section{References}

[1] J.-M. Tarascon, M. Armand, Issues and challenges facing rechargeable lithium batteries, in: Materials for Sustainable Energy, pp. 171-179.

[2] B. Diouf, R. Pode, Potential of lithium-ion batteries in renewable energy, Renewable Energy, 76 (2015) 375-380.

[3] L. Lu, X. Han, J. Li, J. Hua, M. Ouyang, A review on the key issues for lithium-ion battery management in electric vehicles, Journal of Power Sources, 226 (2013) 272-288. [4] D.A. Notter, M. Gauch, R. Widmer, P. Wäger, A. Stamp, R. Zah, H.-J. Althaus, Contribution of Li-Ion Batteries to the Environmental Impact of Electric Vehicles, Environmental Science \& Technology, 44 (2010) 6550-6556.

[5] J.W. Choi, D. Aurbach, Promise and reality of post-lithium-ion batteries with high energy densities, Nature Reviews Materials, 1 (2016) 16013.

[6] V. Etacheri, R. Marom, R. Elazari, G. Salitra, D. Aurbach, Challenges in the development of advanced Li-ion batteries: a review, Energy \& Environmental Science, 4 (2011) 3243-3262.

[7] W. Waag, C. Fleischer, D.U. Sauer, Critical review of the methods for monitoring of lithium-ion batteries in electric and hybrid vehicles, Journal of Power Sources, 258 (2014) 321-339.

[8] B. Scrosati, J. Hassoun, Y.-K. Sun, Lithium-ion batteries. A look into the future, Energy \& Environmental Science, 4 (2011) 3287-3295.

[9] G. Pistoia, Lithium-Ion Batteries: Advances and Applications, Elsevier Science, 2013.

[10] K.E. Aifantis, S.A. Hackney, R.V. Kumar, High Energy Density Lithium Batteries: Materials, Engineering, Applications, Wiley, 2010.

[11] P. Arora, Z. Zhang, Battery Separators, Chemical Reviews, 104 (2004) 4419-4462. 
[12] H. Zhang, X. Wang, Y. Liang, Preparation and characterization of a Lithium-ion battery separator from cellulose nanofibers, Heliyon, 1 (2015) e00032.

[13] C.M. Costa, M.M. Silva, S. Lanceros-Méndez, Battery separators based on vinylidene fluoride (VDF) polymers and copolymers for lithium ion battery applications, RSC Advances, 3 (2013) 11404-11417.

[14] F. Yan, W.A. Goedel, A Simple and Effective Method for the Preparation of Porous Membranes with Three-Dimensionally Arranged Pores, Advanced Materials, 16 (2004) 911-915.

[15] X.Q. Yang, H.S. Lee, L. Hanson, J. McBreen, Y. Okamoto, Development of a new plasticizer for poly(ethylene oxide)-based polymer electrolyte and the investigation of their ion-pair dissociation effect, Journal of Power Sources, 54 (1995) 198-204.

[16] O. Nishikawa, T. Sugimoto, S. Nomura, K. Doyama, K. Miyatake, H. Uchida, M. Watanabe, Preparation of the electrode for high temperature PEFCs using novel polymer electrolytes based on organic/inorganic nanohybrids, Electrochimica Acta, 50 (2004) 667-672.

[17] J.R. Kim, S.W. Choi, S.M. Jo, W.S. Lee, B.C. Kim, Electrospun PVdF-based fibrous polymer electrolytes for lithium ion polymer batteries, Electrochimica Acta, 50 (2004) 69-75.

[18] Z. Li, F. Shan, J. Wei, J. Yang, X. Li, X. Wang, High ionic conductive PVDF-based fibrous electrolytes, Journal of Solid State Electrochemistry, 12 (2008) 1629-1635.

[19] K.M. Abraham, Z. Jiang, B. Carroll, Highly Conductive PEO-like Polymer Electrolytes, Chemistry of Materials, 9 (1997) 1978-1988.

[20] S. Sylla, J.Y. Sanchez, M. Armand, Electrochemical study of linear and crosslinked POE-based polymer electrolytes, Electrochimica Acta, 37 (1992) 1699-1701.

[21] C.M. Costa, M. Kundu, V.F. Cardoso, A.V. Machado, M.M. Silva, S. LancerosMéndez, Silica/poly(vinylidene fluoride) porous composite membranes for lithium-ion battery separators, Journal of Membrane Science, 564 (2018) 842-851.

[22] Y.S. Chung, S.H. Yoo, C.K. Kim, Enhancement of Meltdown Temperature of the Polyethylene Lithium-Ion Battery Separator via Surface Coating with Polymers Having High Thermal Resistance, Industrial \& Engineering Chemistry Research, 48 (2009) 43464351.

[23] G. Venugopal, J. Moore, J. Howard, S. Pendalwar, Characterization of microporous separators for lithium-ion batteries, Journal of Power Sources, 77 (1999) 34-41. 
[24] B.K. Choi, K.H. Shin, Y.W. Kim, Lithium ion conduction in PEO-salt electrolytes gelled with PAN, Solid State Ionics, 113-115 (1998) 123-127.

[25] Y. Kang, H.J. Kim, E. Kim, B. Oh, J.H. Cho, Photocured PEO-based solid polymer electrolyte and its application to lithium-polymer batteries, Journal of Power Sources, 92 (2001) 255-259.

[26] B. Huang, Z. Wang, G. Li, H. Huang, R. Xue, L. Chen, F. Wang, Lithium ion conduction in polymer electrolytes based on PAN, Solid State Ionics, 85 (1996) 79-84.

[27] D. Djian, F. Alloin, S. Martinet, H. Lignier, Macroporous poly(vinylidene fluoride) membrane as a separator for lithium-ion batteries with high charge rate capacity, Journal of Power Sources, 187 (2009) 575-580.

[28] C.M. Costa, A. California, V.F. Cardoso, V. Sencadas, L.C. Rodrigues, M.M. Silva, S. Lanceros-Méndez, Electroactive Poly(Vinylidene Fluoride-Trifluorethylene) (PVDFTrFE) Microporous Membranes for Lithium-Ion Battery Applications, Ferroelectrics, 430 (2012) 103-107.

[29] C.M. Costa, L.C. Rodrigues, V. Sencadas, M.M. Silva, S. Lanceros-Méndez, Effect of the microsctructure and lithium-ion content in poly[(vinylidene fluoride)-cotrifluoroethylene]/lithium perchlorate trihydrate composite membranes for battery applications, Solid State Ionics, 217 (2012) 19-26.

[30] C.M. Costa, L.C. Rodrigues, V. Sencadas, M.M. Silva, G. Rocha, S. LancerosMéndez, Effect of degree of porosity on the properties of poly(vinylidene fluoridetrifluorethylene) for Li-ion battery separators, Journal of Membrane Science, 407-408 (2012) 8 .

[31] H. Liu, J. Xu, B. Guo, X. He, Preparation and performance of silica/polypropylene composite separator for lithium-ion batteries, Journal of Materials Science, 49 (2014) 6961-6966.

[32] C. Martinez-Cisneros, C. Antonelli, B. Levenfeld, A. Varez, J.Y. Sanchez, Evaluation of polyolefin-based macroporous separators for high temperature Li-ion batteries, Electrochimica Acta, 216 (2016) 68-78.

[33] W. Kang, N. Deng, X. Ma, J. Ju, L. Li, X. Liu, B. Cheng, A thermostability gel polymer electrolyte with electrospun nanofiber separator of organic F-doped poly-mphenyleneisophthalamide for lithium-ion battery, Electrochimica Acta, 216 (2016) 276286.

[34] A. Banerjee, B. Ziv, Y. Shilina, S. Luski, I.C. Halalay, D. Aurbach, Multifunctional Manganese Ions Trapping and Hydrofluoric Acid Scavenging Separator for Lithium Ion 
Batteries Based on Poly(ethylene-alternate-maleic acid) Dilithium Salt, Advanced Energy Materials, 7 (2017) 1601556.

[35] J. Saunier, F. Alloin, J.Y. Sanchez, L. Maniguet, Plasticized microporous poly(vinylidene fluoride) separators for lithium-ion batteries. III. Gel properties and irreversible modifications of poly(vinylidene fluoride) membranes under swelling in liquid electrolytes, Journal of Polymer Science Part B: Polymer Physics, 42 (2004) 23082317.

[36] T. Nakajima, H. Groult, Fluorinated Materials For Energy Conversion, Elsevier, 2005 .

[37] J. Li, Exchange Coupling in P(VDF-TrFE) Copolymer Based All-Organic Composites with Giant Electrostriction, Physical Review Letters, 90 (2003) 217601.

[38] J. Nunes-Pereira, A.C. Lopes, C.M. Costa, L.C. Rodrigues, M.M. Silva, S. LancerosMéndez, Microporous membranes of $\mathrm{NaY}$ zeolite/poly(vinylidene fluoridetrifluoroethylene) for Li-ion battery separators, Journal of Electroanalytical Chemistry, 689 (2013) 223-232.

[39] J. Nunes-Pereira, C.M. Costa, R.E. Sousa, A.V. Machado, M.M. Silva, S. LancerosMéndez, Li-ion battery separator membranes based on barium titanate and poly(vinylidene fluoride-co-trifluoroethylene): Filler size and concentration effects, Electrochimica Acta, 117 (2014) 276-284.

[40] J. Nunes-Pereira, C.M. Costa, R. Leones, M.M. Silva, S. Lanceros-Méndez, Li-ion battery separator membranes based on poly(vinylidene fluoride-trifluoroethylene)/carbon nanotube composites, Solid State Ionics, 249-250 (2013) 63-71.

[41] J. Nunes-Pereira, A.C. Lopes, C.M. Costa, R. Leones, M.M. Silva, S. LancerosMéndez, Porous Membranes of Montmorillonite/Poly(vinylidene fluoridetrifluorethylene) for Li-Ion Battery Separators, Electroanalysis, 24 (2012) 2147-2156.

[42] J. Nunes-Pereira, M. Kundu, A. Gören, M.M. Silva, C.M. Costa, L. Liu, S. LancerosMéndez, Optimization of filler type within poly(vinylidene fluoride-co-trifluoroethylene) composite separator membranes for improved lithium-ion battery performance, Composites Part B: Engineering, 96 (2016) 94-102.

[43] M. Kundu, C.M. Costa, J. Dias, A. Maceiras, J.L. Vilas, S. Lanceros-Méndez, On the Relevance of the Polar $\beta$-Phase of Poly(vinylidene fluoride) for High Performance Lithium-Ion Battery Separators, The Journal of Physical Chemistry C, 121 (2017) 2621626225.

[44] M. Yang, J. Hou, Membranes in Lithium Ion Batteries, Membranes, 2 (2012) 367. 
[45] D. Miranda, C.M. Costa, A.M. Almeida, S. Lanceros-Méndez, Modeling separator membranes physical characteristics for optimized lithium ion battery performance, Solid State Ionics, 278 (2015) 78-84.

[46] C. Ribeiro, C.M. Costa, D.M. Correia, J. Nunes-Pereira, J. Oliveira, P. Martins, R. Gonçalves, V.F. Cardoso, S. Lanceros-Méndez, Electroactive poly(vinylidene fluoride)based structures for advanced applications, Nature Protocols, 13 (2018) 681.

[47] V. Sencadas, S. Lanceros-Méndez, J.F. Mano, Characterization of poled and nonpoled $\beta$-PVDF films using thermal analysis techniques, Thermochimica Acta, 424 (2004) 201-207.

[48] 9 - Introduction to Vinylidene Fluoride Polymers, in: S. Ebnesajjad (Ed.) Introduction to Fluoropolymers, William Andrew Publishing, Oxford, 2013, pp. 133-148. [49] X. Wu, J. Lee, V. Varshney, J.L. Wohlwend, A.K. Roy, T. Luo, Thermal Conductivity of Wurtzite Zinc-Oxide from First-Principles Lattice Dynamics - a Comparative Study with Gallium Nitride, Scientific Reports, 6 (2016) 22504.

[50] A. Gören, J. Mendes, H.M. Rodrigues, R.E. Sousa, J. Oliveira, L. Hilliou, C.M. Costa, M.M. Silva, S. Lanceros-Méndez, High performance screen-printed electrodes prepared by a green solvent approach for lithium-ion batteries, Journal of Power Sources, 334 (2016) 65-77.

[51] S. Remanan, M. Sharma, S. Bose, N.C. Das, Recent Advances in Preparation of Porous Polymeric Membranes by Unique Techniques and Mitigation of Fouling through Surface Modification, ChemistrySelect, 3 (2018) 609-633.

[52] M.P. Silva, G. Botelho, J.G. Rocha, S. Lanceros-Mendez, Stability of the electroactive response of $\beta$-poly(vinylidene fluoride) for applications in the petrochemical industry, Polymer Testing, 29 (2010) 613-615.

[53] T.W. Quadri, L.O. Olasunkanmi, O.E. Fayemi, M.M. Solomon, E.E. Ebenso, Zinc Oxide Nanocomposites of Selected Polymers: Synthesis, Characterization, and Corrosion Inhibition Studies on Mild Steel in HCl Solution, ACS Omega, 2 (2017) 8421-8437.

[54] C.M. Costa, M.N.T. Machiavello, J.L.G. Ribelles, S. Lanceros-Méndez, Composition-dependent physical properties of poly[(vinylidene fluoride)-cotrifluoroethylene]-poly(ethylene oxide) blends, Journal of Materials Science, 48 (2013) 3494-3504.

[55] S. Lanceros-Méndez, J.F. Mano, A.M. Costa, V.H. Schmidt, FTIR AND DSC STUDIES OF MECHANICALLY DEFORMED $\beta$-PVDF FILMS, Journal of Macromolecular Science, Part B, 40 (2001) 517-527. 
[56] S. Kalnaus, Y. Wang, J.A. Turner, Mechanical behavior and failure mechanisms of Li-ion battery separators, Journal of Power Sources, 348 (2017) 255-263.

[57] W. Li, Y. Zhu, D. Hua, P. Wang, X. Chen, J. Shen, Crystalline morphologies of $\mathrm{P}(\mathrm{VDF}-\mathrm{TrFE})$ (70/30) copolymer films above melting point, Applied Surface Science, 254 (2008) 7321-7325.

[58] T. Michot, A. Nishimoto, M. Watanabe, Electrochemical properties of polymer gel electrolytes based on poly(vinylidene fluoride) copolymer and homopolymer, Electrochimica Acta, 45 (2000) 1347-1360.

[59] S. Yan, J. Deng, C. Bae, X. Xiao, Thermal expansion/shrinkage measurement of battery separators using a dynamic mechanical analyzer, Polymer Testing, 71 (2018) 6571.

[60] N.H. Idris, M.M. Rahman, J.-Z. Wang, H.-K. Liu, Microporous gel polymer electrolytes for lithium rechargeable battery application, Journal of Power Sources, 201 (2012) 294-300.

[61] Y. Zhu, S. Xiao, Y. Shi, Y. Yang, Y. Hou, Y. Wu, A Composite Gel Polymer Electrolyte with High Performance Based on Poly(Vinylidene Fluoride) and Polyborate for Lithium Ion Batteries, Advanced Energy Materials, 4 (2014) 1300647.

[62] B.-Y. Chang, S.-M. Park, Electrochemical Impedance Spectroscopy, Annual Review of Analytical Chemistry, 3 (2010) 207-229.

[63] J. Hassoun, D.-J. Lee, Y.-K. Sun, B. Scrosati, A lithium ion battery using nanostructured $\mathrm{Sn}-\mathrm{C}$ anode, $\mathrm{LiFePO} 4$ cathode and polyethylene oxide-based electrolyte, Solid State Ionics, 202 (2011) 36-39.

[64] J. Landesfeind, J. Hattendorff, A. Ehrl, W.A. Wall, H.A. Gasteiger, Tortuosity Determination of Battery Electrodes and Separators by Impedance Spectroscopy, Journal of The Electrochemical Society, 163 (2016) A1373-A1387.

[65] D. Anseán, M. González, J.C. Viera, J.C. Álvarez, C. Blanco, V.M. García, Evaluation of LiFePO<inf >4</inf> batteries for Electric Vehicle applications, in: 2013 International Conference on New Concepts in Smart Cities: Fostering Public and Private Alliances (SmartMILE), 2013, pp. 1-8.

[66] L. Damen, J. Hassoun, M. Mastragostino, B. Scrosati, Solid-state, rechargeable $\mathrm{Li} / \mathrm{LiFePO} 4$ polymer battery for electric vehicle application, Journal of Power Sources, 195 (2010) 6902-6904. 
[67] Y.-H. Nien, J.R. Carey, J.-S. Chen, Physical and electrochemical properties of $\mathrm{LiFePO} 4 / \mathrm{C}$ composite cathode prepared from various polymer-containing precursors, Journal of Power Sources, 193 (2009) 822-827.

[68] S.-X. Zhao, H. Ding, Y.-C. Wang, B.-H. Li, C.-W. Nan, Improving rate performance of LiFePO4 cathode materials by hybrid coating of nano-Li3PO4 and carbon, Journal of Alloys and Compounds, 566 (2013) 206-211.

[69] I.V. Thorat, T. Joshi, K. Zaghib, J.N. Harb, D.R. Wheeler, Understanding RateLimiting Mechanisms in LiFePO4 Cathodes for Li-Ion Batteries, Journal of The Electrochemical Society, 158 (2011) A1185-A1193.

[70] R.E. Sousa, J. Nunes-Pereira, C.M. Costa, M.M. Silva, S. Lanceros-Méndez, J. Hassoun, B. Scrosati, G.B. Appetecchi, Influence of the porosity degree of poly(vinylidene fluoride-co-hexafluoropropylene) separators in the performance of Liion batteries, Journal of Power Sources, 263 (2014) 29-36.

[71] H.-q. Liang, L.-s. Wan, Z.-k. Xu, Poly(vinylidene fluoride) separators with dualasymmetric structure for high-performance lithium ion batteries, Chinese Journal of Polymer Science, 34 (2016) 1423-1435.

[72] C.M. Costa, H.M. Rodrigues, A. Gören, A.V. Machado, M.M. Silva, S. LancerosMéndez, Preparation of Poly(vinylidene fluoride) Lithium-Ion Battery Separators and Their Compatibilization with Ionic Liquid - A Green Solvent Approach, ChemistrySelect, 2 (2017) 5394-5402.

[73] N. Angulakshmi, A.M. Stephan, Electrospun Trilayer Polymeric Membranes as Separator for Lithium-ion Batteries, Electrochimica Acta, 127 (2014) 167-172.

[74] J. Zhang, B. Sun, X. Huang, S. Chen, G. Wang, Honeycomb-like porous gel polymer electrolyte membrane for lithium ion batteries with enhanced safety, Scientific Reports, 4 (2014) 6007.

[75] R.E. Sousa, M. Kundu, A. Gören, M.M. Silva, L. Liu, C.M. Costa, S. LancerosMendez, Poly(vinylidene fluoride-co-chlorotrifluoroethylene) (PVDF-CTFE) lithiumion battery separator membranes prepared by phase inversion, RSC Advances, 5 (2015) 90428-90436.

[76] H. Lee, M. Alcoutlabi, O. Toprakci, G. Xu, J.V. Watson, X. Zhang, Preparation and characterization of electrospun nanofiber-coated membrane separators for lithium-ion batteries, Journal of Solid State Electrochemistry, 18 (2014) 2451-2458. 